Original Paper

\title{
Optimalisasi Pemanfaatan Lahan Pekarangan Sebagai Upaya dalam Membantu Ketersediaan Pangan dan Perekonomian Masyarakat di Desa Sukarema, Kabupaten Lombok Timur
}

\author{
Kurniasih Sukenti $^{1}$, Sukiman ${ }^{1}$, Suripto ${ }^{1}$, Immy Suci Rohyani ${ }^{1 *}$, Ahmad Jupri ${ }^{1}$ \\ ${ }^{1}$ Program Studi Biologi FMIPA Universitas Mataram, Indonesia
}

DOI: $10.29303 /$ jpmpi.v2i1.362

Sitasi: Sukenti, K., Sukiman., Suripto., Rohayni, I. S., Jupri, A. (2019). Optimalisasi Pemanfaatan Lahan Pekarangan Sebagai Upaya dalam Membantu Ketersediaan Pangan dan Perekonomian Masyarakat di Desa Sukarema, Kabupaten Lombok Timur. Jurnal Pengabdian Magister Pendidikan IPA (JPMPI). (2) 1. pp. 97-101

*Corresponding Author: Immy Suci Rohani, Program Studi Biologi FMIPA Universitas Mataram, Indonesia;

Email: immysuci@yahoo.co.id

\begin{abstract}
Abstrak: Keanekaragaman jenis tumbuhan di Indonesia pada dasarnya juga diikuti dengan beragamnya potensi pemanfaatan jenis-jenis tumbuhan, termasuk di antaranya tanaman pangan dan obat-obatan. Penggunaan obat tradisional oleh masyarakat adakalanya masih menjadi prioritas utama dalam mengobati beberapa jenis penyakit. Selain berkhasiat, obat-obatan berbahan alam tidak memiliki efek samping sebesar obat-obatan medis, asalkan digunakan sesuai dosis yang dianjurkan. Selain itu juga relatif lebih ekonomis dan beberapa jenis di antaranya mudah dijumpai di lingkungan sekitar tempat tinggal. Lahan pekarangan masyarakat merupakan lokasi yang potensial untuk membudidayakan tanaman pangan dan obat-obatan, setidaknya untuk keperluan dalam skala rumah tangga. Namun kendala yang sering dihadapi adalah terbatasnya lahan pekarangan karena telah digunakan untuk keperluan lainnya, selain juga adanya kendala lain yang menyebabkan masyarakat belum giat melakukan penanman di sekitar lahan pekarangan. Oleh karena itu diperlukan teknik bertanam yang tidak banyak memakan tempat, yang bahkan bisa juga diterapkan pada jenis tanaman lain misalnya tanaman sayur-sayuran untuk keperluan rumah tangga. Tujuan kegiatan ini adalah untuk memberikan sosialisasi dan pelatihan pada warga masyarakat agar memiliki pengetahuan dan keterampilan dalam melakukan optimalisasi lahan pekarangan, dengan penanaman tanaman sayur dan tanaman obat menggunakan teknik vertikultur. Diharapkan hal ini dapat membantu upaya pemeliharaan kesehatan dan ketersediaan pangan untuk skala rumah tangga.
\end{abstract}

Kata kunci: Pekarangan; Tanaman Sayur; Tanaman Ibat; Vertikuktur

\section{Pendahuluan}

Pekarangan adalah lahan terbuka yang terdapat di sekitar rumah tinggal. Lahan pekarangan merupakan salah satu lahan potensial yang dapat dimanfaatkan untuk menanam tanaman seperti tanaman hias, buah-buahan, sayur-mayur, rempahrempah, dan obat-obatan. Pemanfaatan lahan pekarangan untuk pengembangan industri rumah tangga merupakan salah

satu alternatif untuk mewujudkan kemandirian ekonomi rumah tangga (Kurnianingsih dkk., 2013).

Peranan dan pemanfaatan pekarangan bervariasi di antara suatu wilayah dengan wilayah lainnya, dimana hal ini juga dipengaruhi oleh tingkat kebutuhan, sosial budaya, pendidikan masyarakat, maupun faktor fisik dan ekologi wilayah setempat (Khomah \& Fajarningsih, 2015). Menurut Rahayu $d k k$. (2005), pekarangan jika dikelola dengan baik akan berpotensi menambah penghasilan keluarga, sehingga peranan lahan pekarangan secara tidak langsung mampu mempengaruhi perekonomi rumah tangga.

Desa Sukarema merupakan salah satu desa di wilayah Aikmel, Kabupaten Lombok Timur. Berdasarkan observasi, mayoritas penduduknya adalah petani padi dan jenis komoditas lainnya, serta sebagian lagi bermata-pencaharian sebagai 
peternak sapi. Aktivitas bercocoktanam masyarakat secara umum diprioritaskan di lahan persawahan dan sekitarnya, baik pematang maupun sebagai pembatas lahan. Animo masyarakat untuk melakukan penanaman di lahan pekarangan belum terlalu besar terutama karena lahan pekarangan yang tidak terlalu luas, juga karena adanya gangguan dari hewan-hewan ternak unggas (ayam, bebek) di sekitarnya. Hal ini menyebabkan terganggunya kelangsungan hidup tanaman pekarangan karena sebagian dikonsumsi oleh unggas. Perlu adanya suatu upaya untuk membuat masyarakat tergerak dalam mengoptimalisasikan lahan pekarangan yang dimiliki, agar selain berguna bagi keperluan rumah tangga juga dapat berguna untuk mendukung perekonomian keluarga.

Tujuan kegiatan ini adalah untuk memberikan sosialisasi dan pelatihan pada warga masyarakat agar memiliki pengetahuan dan keterampilan dalam melakukan optimalisasi lahan pekarangan, dengan penanaman tanaman sayur dan tanaman obat menggunakan teknik vertikultur. Diharapkan dengan adanya kegiatan ini masyarakat memiliki solusi dalam memanfaatkan lahan pekarangan yang belum optimal, selain juga untuk membantu ketersediaan pangan dan obat untuk skala rumah tangga, serta berpotensi untuk menambah penghasilan keluarga.

\section{Metode Pelaksanaan}

Dalam kegiatan ini digunakan beberapa metode kegiatan, antara lain sebagai berikut:

1. Tahap Persiapan, meliputi studi pustaka, survei pendahuluan untuk mengidentifikasi permasalahan, pengurusan perijinan pelaksanaan kegiatan, dan sosialisasi rencana kegiatan pada masyarakat

2. Penyuluhan tentang optimalisasi pemanfaatan lahan pekarangan dengan tanaman sayur dan tanaman obat, dengan sistem bertanam vertikultur

3. Demonstrasi dan pelaksanaan pembuatan pot vertikultur, penyiapan media tanam, penanaman dan pemeliharaan tanaman pekarangan

Dalam kegiatan penyuluhan dan demonstrasi, dilakukan pula pendampingan cara penanaman tumbuhan obat dan sayur-sayuran dengan beberapa metode, yaitu: penanaman menggunakan pot, penanaman menggunakan polybag, dan penanaman dengan sistem vertikultur menggunakan bahan-bahan sederhana misalnya botol bekas air mineral/minuman, bambu, pipa paralon, ember atau kaleng tidak terpakai, dan sebagainya

Kegiatan penyuluhan dilakukan terhadap warga masyarakat sekitar di lokasi kegiatan pengabdian, dengan materi mengenai optimalisasi lahan pekarangan dengan penanaman tumbuhan obat dan sayuran, beserta manfaat dan budidayanya. Kegiatan demonstrasi meliputi cara budidaya (penanaman dan pemeliharaan), sekaligus demonstrasi serta visualisasi cara penyiapan sarana sistem vertikultur. Hal ini disertai dengan pendampingan selama masa sesudah penanaman, dimana kegiatan selanjutnya akan diarahkan pada pemupukan menggunakan pupuk organik.

Penyediaan bibit dilakukan dengan membeli bibit beberapa jenis tanaman pekarangan, antara lain tanaman cabai rawit, cabai besar, terong, dan tomat. Bibit tanaman obat (rempah-rempah) direncanakan menggunakan jenis-jenis yang telah dimiliki oleh warga setempat, yang telah melakukan penanaman sebelumnya untuk memenuhi kebutuhan dapur rumah tangga.

\section{Hasil dan Pembahasan}

Program ini dilaksanakan di Dusun Lendang Kantong, Desa Sukarema, Kecamatan Aikmel, Kabupaten Lombok Timur. Kegiatan dilakukan bersamaan dengan kegiatan penyuluhan dan pelatihan pembuatan pupuk cair organik menggunakan limbah peternakan sapi oleh Laboratorium Riset Mikrobiologi FMIPA Universitas Mataram, sehingga masyarakat target adalah beberapa perwakilan dari kelompok peternak di Desa Sukarema, beserta perwakilan kelompok ibu-ibu PKK dan warga setempat. Peserta kegiatan seluruhnya berjumlah 20 orang, terdiri atas wakil dari kelompok peternak, organisasi PKK, dan warga masyarakat yang telah ditugaskan oleh kantor desa. Kegiatan, bertempat di kelompok ternak Tunggal Harapan, Dusun Lendang Kantong, Desa Sukarema, Kecamatan Aikmel, Lombok Timur.

Pemaparan materi disertai dengan demonstrasi dan pendampingan terkait optimalisasi lahan pekarangan, pemanfaatan tanaman sayur dan tanaman obat, dan cara budidayanya. Berikut rincian kegiatan:

a) Pemaparan materi berisi sosialisasi cara optimalisasi lahan pekarangan dengan metode penanaman vertikultur, yaitu penanaman yang 
dilakukan bersusun vertikal ke atas, baik menggunakan pot, polybag, maupun sarana lain seperti botol air mineral bekas, kaleng cat, ban bekas, rak kayu, dan berbagai wadah yang tidak terpakai lagi. Tujuan metode vertikultur adalah untuk menghemat tempat, dimana tanaman yang ditanam (dalam pot, wadah, kaleng, botol bekas, dan sebagainya) kemudian ditempatkan atau disusun secara vertikal (bertingkat ke atas). Dengan metode demikian maka lahan yang terbatas pun dapat dimanfaatkan secara optimal. Pada kesempatan ini juga dilakukan diskusi dan tanya jawab mengenai permasalahan yang ada terkait pemanfaatan lahan pekarangan masyarakat, dengan narasumber tim pengabdian.

b) Demonstrasi penyiapan pot dan media vertikultur dilakukan dengan memperagakan secara garis besar cara menyiapkan pot vertikultur beserta rak vertikultur (Gambar 1), dimana pot menggunakan pot plastik dan sebagian lainnya menggunakan plastik polybag (Gambar 2). Rak vertikultur menggunakan bahan dari bambu dan kayu, dibuat bersusun 3 (Gambar 3). Dengan menggunakan rak vertikultur maka selain dapat menghemat tempat, juga tanaman akan terhindar dari gangguan hewan ternak (ayam dan unggas lainnya). Selain itu juga posisi rak dapat dipindahpindahkan disesuaikan dengan situasi dan kondisi (sinar matahari, kondisi hujan, dan sebagainya). Dilakukan juga pembuatan pot vertikultur yang ditujukan untuk digantung di dinding atau tembok (Gambar 4), selain untuk menghemat tempat juga untuk mengisi ruang kosong agar dapat menambah nilai estetis. Hal ini potensial dilakukan karena beberapa bangunan dan rumah warga masih memungkinkan untuk dijadikan tempat pot vertikultur gantung.

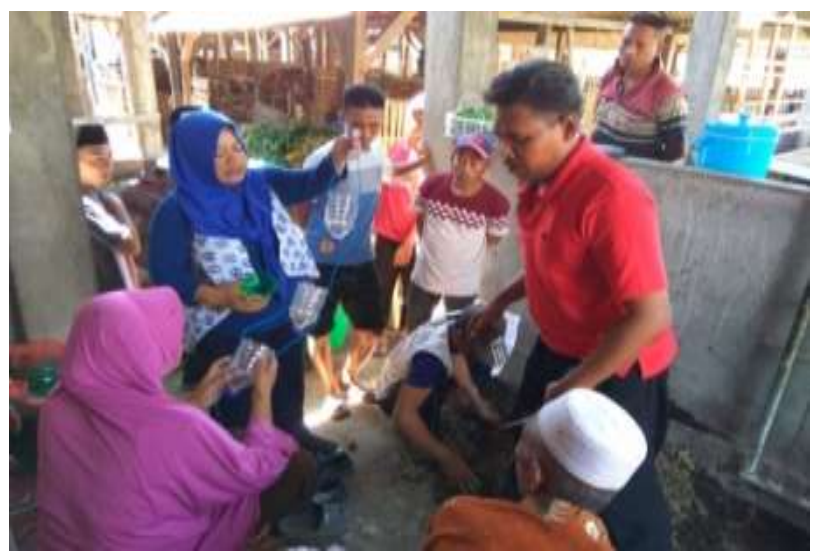

Gambar 1. Penyiapan pot vertikultur

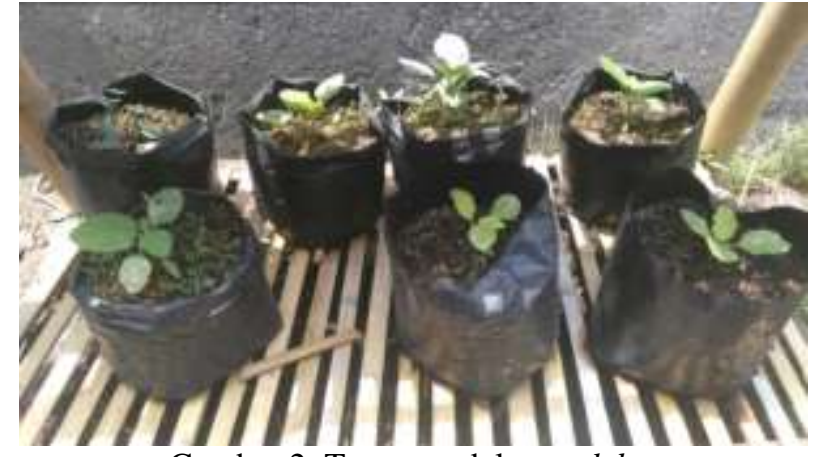

Gambar 2. Tanaman dalam polybag

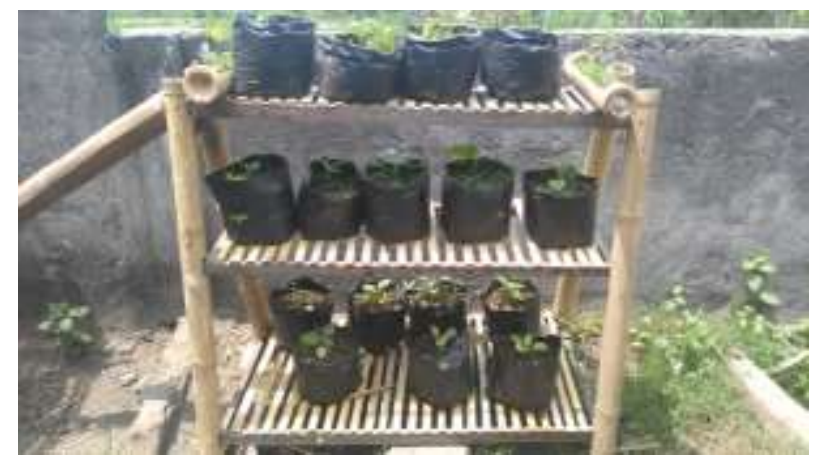

Gambar 3. Rak vertikultur

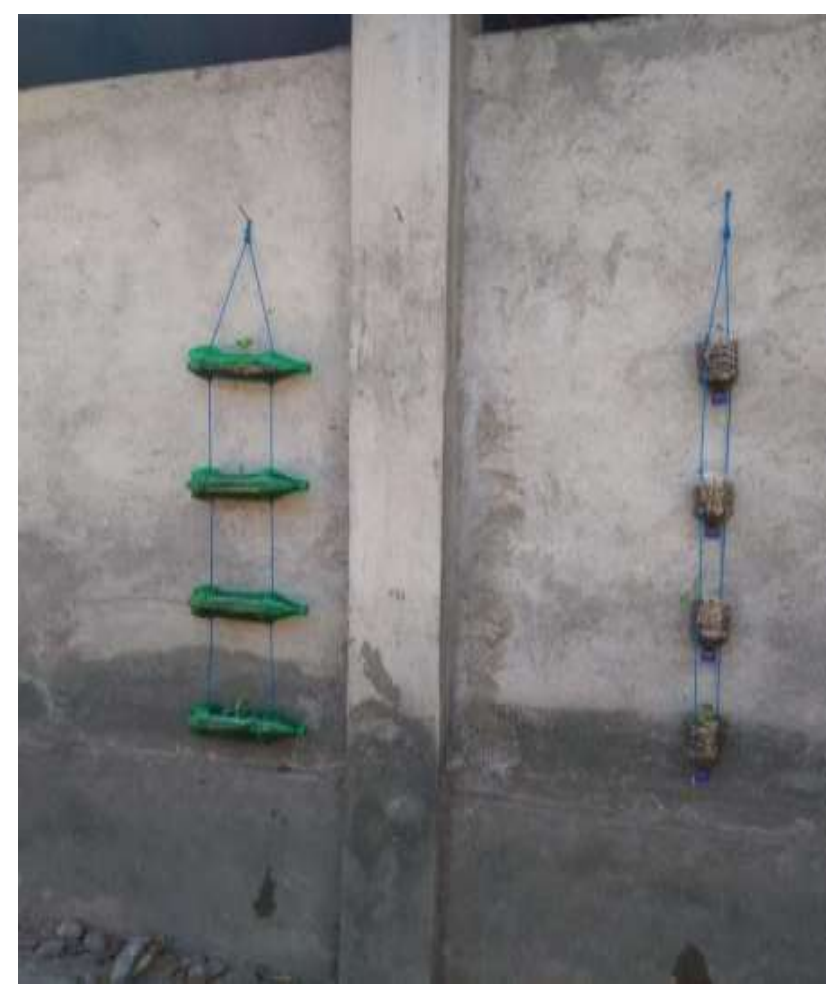

Gambar 4. Pot gantung

c. Praktek penanaman bibit dilakukan secara bersama-sama, dimulai dengan penyiapan media tanam dengan mencampur tanah kompos dan sekam dengan perbandingan 1:1. Bibit yang telah 
tersedia adalah terong, tomat, cabai rawit, cabai besar, dan beberapa tanaman rimpang dari famili Zingiberaceae. Bibit-bibit tanaman yang telah dipersiapkan sebelumnya itu ditanam di pot vertikultur gantung yang telah disiapkan (terbuat botol air mineral bekas) dan polybag, menggunakan media tanam yang telah dicampur (Gambar 5). tanaman pada polybag kemudian disusun pada rak vertikultur (Gambar 6).

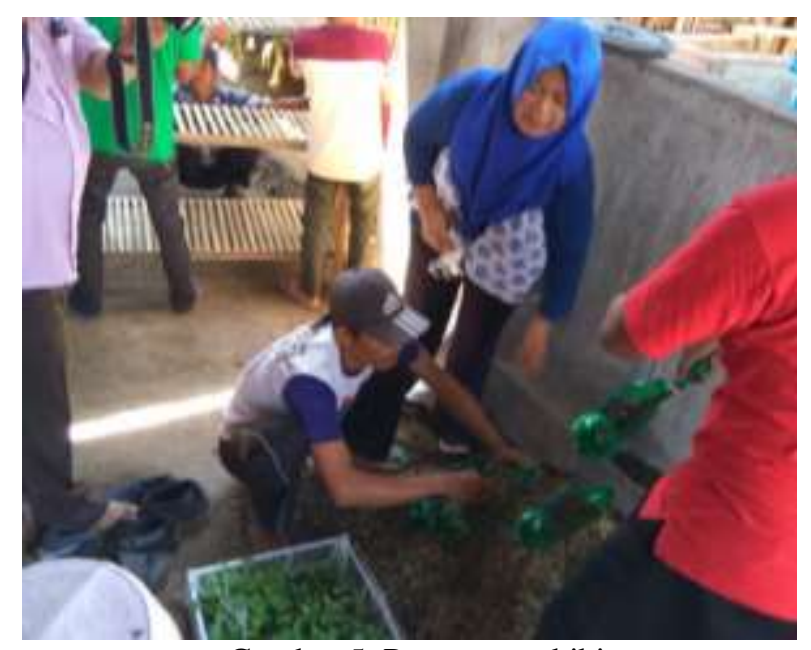

Gambar 5. Penanaman bibit

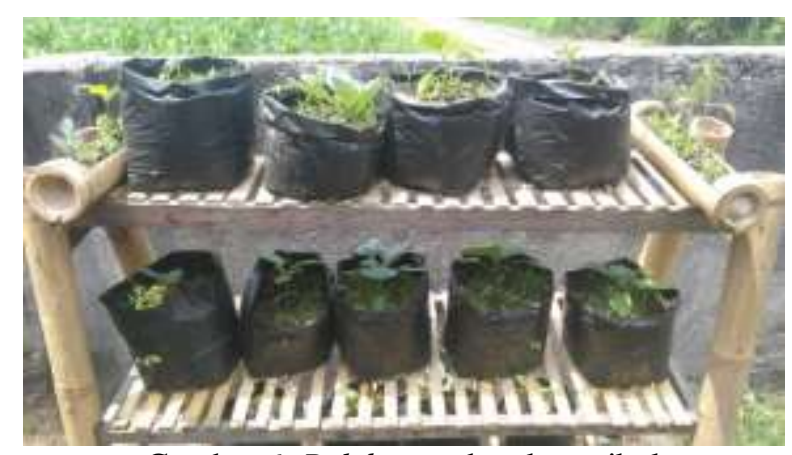

Gambar 6. Polybag pada rak vertikultur

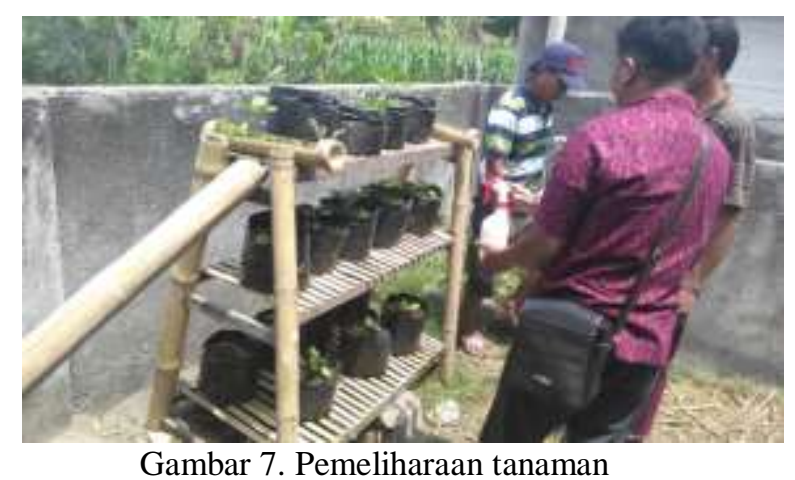

Pemeliharaan tanaman dilakukan dengan penyiraman secara berkala oleh warga masyarakat.
Sementara itu penyiraman menggunakan pupuk cair organik yang berasal dari limbah kotoran sapi dilakukan pada 2 minggu berikutnya, sebab pupuk cair memerlukan masa fermentasi. Kemudian setelah 2 minggu dilakukan penyiraman menggunakan pupuk cair organik, pada seluruh tanaman yang telah ditanam (Gambar 7). Penyiraman dengan pupuk cair ini dilakukan secara berselang-seling (bergantian) dengan air biasa (air sumur) setiap 2 hari sekali.

Pencapaian tujuan kegiatan terlihat dari antusiasme warga yang cukup baik dalam mengikuti setiap tahapan sosialisasi dan pelatihan. Jenis sayuran atau tanaman yang digunakan dapat disesuaikan dengan keinginan dan kebutuhan masyarakat, atau disesuaikan dengan kebutuhan pasar jika memang suatu saat budidaya ini akan dilanjutkan hingga bernilai ekonomi bagi masyarakat. Jenis tanaman yang sesuai umumnya yang memiliki nilai ekonomi tinggi namun berumur pendek, misalnya tanaman semusim berupa sayuran seledri, caisim, selada, dan berbagai jenis sawi (Khomah \& Fajarningsih, 2015; Kusmiati \& Solikhah, 2015). Pemilihan jenis tanaman pada tiap rumah tangga adakalanya bergantung pada pilihan rumah tangga yang lainnya, karena masyarakat pada dasarnya membutuhkan contoh nyata sebelum mengambil keputusan (Haryati \& Sukmaya, 2016; Juanda dkk., 2012).

Selain itu capaian tujuan kegiatan juga didukung oleh ketersediaan sarana pendukung. Selain bahan-bahan untuk membuat pot dan rak vertikultur yang mudah ditemukan di wilayah sekitar, juga bibit dan pupuk organik telah tersedia dengan mencukupi di wilayah sasaran. Selain sebagai petani, warga masyarakat juga banyak yang berprofesi sebagai peternak sapi, sehingga limbah peternakan sapi dapat dimanfaatkan dan diaplikasikan dalam pemupukan tanaman sayur dan tanaman obat. Pada dasarnya lahan yang masih luas di wilayah pedesaan sangat potensial bagi diterapkannya budidaya semacam ini, dimana dapat pula diselingi dengan pengadaan kandang ternak, kolam ikan, tanaman pagar, tanaman buah, dan tanaman untuk pakan ternak. Namun jika luasan lahan kurang memungkinkan seperti halnya kebanyakan di wilayah perkotaan, teknik vertikultur merupakan pilihan yang sesuai (Rizal \& Fiana, 2015; Ashari dkk., 2012).

Optimalisasi lahan pekarangan dapat memberikan manfaat antara lain terciptanya kemandirian pangan rumah tangga, diversifikasi 
pangan yang berbasis sumber daya lokal, konservasi tanaman-tanaman pangan, kesejahteraan petani dan masyarakat, menjamin ketersediaan bibit bagi masyarakat, dan antisipasi dampak perubahan iklim. Selain untuk menambah penghasilan keluarga, pekarangan dapat menjamin ketersediaan pangan dan obat rumah tangga, penyaluran hobi dan kreativitas keluarga, menciptakan lingkungan yang nyaman dan sehat, serta mendukung upaya pelestarian ekosistem (Amruddin \& Iqbal, 2018; Hidayat, 2013). Lahan pekarangan tidak hanya sekedar sebagai penyedia bahan pangan dan obatobatan tetapi juga dapat mengurangi pengeluaran konsumsi rumah tangga dan menambah pendapatan rumah tangga, dengan penanaman berbagai komoditas sayur-sayuran, buah-buahan, tanaman rempah, dan tanaman berguna lainnya..

\section{Kesimpulan}

Dari hasil pelaksanaan kegiatan ini dapat disimpulkan bahwa optimalisasi lahan pekarangan dengan penanaman tnaman sayur dan tanaman obat merupakan salah satu upaya yang dapat dilakukan untuk mendukung ketersediaan pangan dan obatobatan keluarga, selain juga bermanfaat untuk menambah nilai estetik lingkungan, penyaluran hobi keluarga, serta pelestarian sumberdaya hayati dan lingkungan.

\section{Daftar Pustaka}

Amruddin, M. Iqbal, (2018). Pemanfaatan Lahan Pekarangan sebagai Upaya Pemenuhan Kebutuhan Keluarga di Desa Kanjilo Kecamatan Barombong Kabupaten Gowa. Ziraa'ah, 43 (1), pp: 70-76.

Ashari, Saptana, Bastuti PT. (2012). Potensi dan Prospek Pemanfaatan Lahan Pekarangan untuk Mendukung Ketahanan Pangan. Pusat Sosial Ekonomi dan Kebijakan Pertanian, Bogor.

Haryati, Y., Sukmaya, (2016). Optimalisasi Pemanfaatan Lahan Pekarangan dalam Mendukung Peningkatan Gizi Keluarga. Buletin Hasil Kajian, 6 (6).

Hidayat, 2013. Studi karakteristik dan fungsi pekarangan di Desa Pasir Eurih Kecamatan
Taman Sari Kabupaten Bogor. Skripsi IPB. Bogor.

Juanda, Erika C, danV.H. Meilliza, (2012). Studi Preferensi Konsumen terhadap Roti Tawar Labu Kuning (Cucurbitamoschata). http://www. google.co.id/url. Diakses pada tanggal 20 Juni 2015.

Khomah, I., R.U. Fajarningsih, (2015). Potensi dan Prospek Pemanfaatan Lahan Pekarangan terhadap Pendapatan Rumah Tangga. Proceeding Seminar Nasional Peningkatan Kapabilitas UMKM dalam Mewujudkan UMKM Naik Kelas.

Kurnianingsih, A., Nusyirwan, Endang Darma Setyati, Yernelis Syawal. (2015). Optimalisasi Lahan Pekarangan dengan Budidaya Tanaman Lidah Buaya yang Berkhasiat Obat di Desa Purna Jaya Kecamatan Indralaya Utara Kabupaten Ogan Ilir. Jurnal Pengabdian Sriwijaya hal. 21-24. Fakultas Pertanian Universitas Sriwijaya.

Kusmiati, A. dan Sholikhah, U. (2015). Peningkatan Pendapatan Keluarga melalui Pemanfaatan Pekarangan Rumah dengan Menggunakan Teknik Vertikultur. Jurnal Inovasi dan Kewirausahaan, 4 (2), Hal. 94101.

Rahayu M, dkk. (2005). Keanekaragaman Tanaman Pekarangan dan Pemanfaatannya di Desa Lampeapi Pulau Wawoni Sulawesi Tenggara. Jurnal Teknologi Lingkungan P3TLBPPT 6 (2):362-36

Rizal, M., Fiana, Y., (2015). Teknologi budidaya tanaman sayuran dan TOGA di perkotaan dan perdesaan pada kawasan rumah pangan lestari dalam mendukung ketahanan pangan di Kalimantan Timur. PROS SEM NAS MASY BIODIV INDON, 1(2), pp: 324-329. 